\title{
Masif alt gastrointestinal sistem kanamasının nadir bir nedeni: İntestinal tüberkülozis
}

\author{
Intestinal tuberculosis: A rare cause of massive lower gastrointestinal system bleeding
}

\author{
(D) Muhammet Yener AKPINAR ${ }^{1}$, \\ (D) Ferdane PİRINÇÇİ SAPMAZ ${ }^{1}$ \\ Doğan ÖZTÜRK², (D) Evrim KAHRAMANOĞLU AKSOY', \\ Gülçin Güler ŞİMŞEK ${ }^{3}$, \\ Sağlık Bilimleri Üniversitesi, Keçiören Eğitim ve Araştırma Hastanesi, ${ }^{1}$ Gastroenteroloji Bölümü, ${ }^{2}$ Genel Cerrahi Bölümü, ${ }^{3}$ Patoloji Bölümü, Ankara
}

\begin{abstract}
Intestinal tüberkülozis, gastrointestinal sistemin tüberküloz basili ile enfekte olma halidir. En sık tutulan bölge ileoçekal alandır. Tutulum yerlerinin benzer olması Crohn hastalığ ile dikkatli bir şekilde ayırıcı tanısının yapılmasını gerektirir. Intestinal tüberküloz klinikte sıklıkla non-spesifik şikayetlerle kendini belli eder. Kanama bu hastalarda sıklıkla kronik seyirlidir. Masif kanama literatürde çok nadir olarak bildirilmiştir. Biz burada cerrahi barsak rezeksiyonu ile hemostazın sağlanabildiği intestinal tüberkülozlu hastamızı sunduk.
\end{abstract}

Anahtar kelimeler: Crohn hastalığı, masif alt gastrointestinal sistem kanaması, tüberküloz

\section{GİRISS}

Tüberküloz gelişmekte olan ülkelerde, beraberinde getirdiği mortalite ve morbidite oranlanı ile önemli bir sağllk sorunu olmaya devam etmektedir (1). Dünya Sağlık Örgütü 2013 verilerine göre ylllk insidansı 8.6 milyon olup 2012 yılında bu hastalıktan ölenlerin sayısı 1.2 milyondur. Tüberkülozun sıklıkla primer kaynağı akciğer olup basil buradan diğer organ ve sistemlere yayllım gösterebilir. Abdominal tüberküloz, pulmoner tüberküloz kadar sı olmasa da önemli bir morbidite ve mortalite kaynağı olabilir. Abdominal tüberkülozu olan hastaların \%25 kadarında eşlik eden pulmoner tüberküloz da vardır (2). Abdominal tüberküloz başlığı altında dört farklı tutulum paterni görülebilir ki tüberküloz lenfadenopati bunlardan en sik görülenidir (3). Peritoneal tüberkülozis, visseral organ tutulumları ve tüberküloz gastroenteriti (TG) ise diğer tutulum şekilleridir.

Tüberküloz gastroenteriti sıklıkla basilin yutulması ile oluşur ve en sık ileoçekal alanı etkiler. Belirtileri spesifik olmayıp etkilenen hastalarda karın ağrısı, ishal, kanama ve/veya apse ile kendini belli edebilir. Kanama genelde hafif ve kronik seyirli olup klinikte demir eksikliği anemisi olarak gözlenir. Masif rektal kanama ise literatürde sayılı hastada bildirilmiştir (4). Biz burada ilke önce Crohn tanısı ile steroid tedavisi başlanan, daha sonra tüberküloz gastroenteriti tanısı alan ve anti-tüberküloz tedavisi altında masif alt gastrointestinal sistem (GIS) kanaması ile kendini gösteren bir olguyu sunduk.
Intestinal tuberculosis is the infection of the gastrointestinal tract by tuberculosis bacilli. The most commonly affected area is the ileocecal region. A careful differential diagnosis between Crohn's disease and intestinal tuberculosis is required because similar areas are involved in both these diseases. Intestinal tuberculosis often presents non-specific complaints in the clinic. Chronic bleeding is often observed in these patients. However, massive bleeding has been reported very rarely in the literature. Herein, we present a patient with intestinal tuberculosis for whom hemostasis was achieved by surgical bowel resection.

Keywords: Crohn's disease, massive lower gastrointestinal system bleeding, tuberculosis

\section{OLGU SUNUMU}

22 yaşında kadın hasta hastanemizin acil servisine dışkıda kanama şikayeti ile başvurdu. Genel durumu iyi ve şuuru açık olan hastanın vitallerinde tansiyonu $90 / 60 \mathrm{mmHg}$ ve nabzi 134/dk olarak tespit edildi. Rektal muayenesinde parlak kırmızı, hematokezya ile uyumlu kanaması tespit edildi. Acil şartlarda hastaya gastroskopi ve kolonoskopi yapılması planlandı ancak hasta ve yakınları bu aşamada bu işlemlerin yapılmasını, yakın zamanda bu işlemler yoğun bir şekilde yapıldığı için, kabul etmedi. Hasta masif gastrointestinal sistem kanaması tanısıyla yoğun bakıma alındı.

Hastanın özgeçmişi sorgulandığında ilk şikayetlerinin karın ağrısı ve ishal olduğu, bu şikayetlerin yaklaşı 6 aydır hastada mevcut olduğu öğrenildi. Hastaya dış merkezde bu şikayetlerinden dolayı kolonoskopi yapılmış ve Crohn hastalı̆ı tanısı konulmuştu. Steroid ve azatiyopürin tedavisi başlanan ve bu ilaçları yaklaşı 2 ay kullanan hastanın şikayetlerinde bir düzelme olmamıştı ve hasta, inflamatuvar barsak hastalıkları açısından yetkin ileri bir merkeze başvurmuştu. Bu merkezde hastaya tekrar gastroskopi ve kolonoskopi yapilmıs, gastroskopi normalken kolonoskopide çekumda yaygın, en büyüğü $3 \mathrm{~cm}$ çaplı ülserler izlenmişti ve terminal ileumda da ülsere alanları görülmüştü. Yapılan histopatoloji ve kültürler ile tüberküloz gastroenteriti tanısı alan hastanın rektal kanamasının bu siralarda hafif olarak başladığı öğrenildi. Yine hastanın acile başvurmadan önce yaklaşık 1 haftadır anti-tüberküloz tedavisi aldığı da öğrenildi.
İletişim: Muhammet Yener AKPINAR Sağlık Bilimleri Üniversitesi, Keçiören Eğitim ve Araştırma Hastanesi, Sanatoryum Caddesi, Keçiören, Ankara・ Tel: +90 3123569000 Fax: + 903123569002 •E-mail: muhammet.yener@gmail.com Geliş Tarihi: 10.12.2019 Kabul Tarihi: 12.12.2019 
Yoğun bakımdaki takiplerde hemoglobin (Hgb) değeri 6 gr/ dl gelen hastaya eritosit süspansiyon verildi ve yakın takibe devam edildi ancak hastanın kanaması artarak devam etti. 12 saatlik sürede 6 ünite eritrosit süspansiyonu verilmesine karşılık hastanın Hgb değeri 6 gr/dl üzerine çıkamadı. Tansiyonu 50/30 mmHg'ya kadar düşen hastaya, önceki mevcut kolonoskopi bulguları temel alınarak çekum kökenli kanama tanısıyla acil şartlarda ameliyat planlandı. Ameliyatı terminal ileumu içine alacak şekilde sağ hemikolektomi olarak planlanılan hastanın intraoperatif eritosit süspansiyonu desteği ile ameliyatı başarılı bir şekilde yapıldı. Çıkarılan barsak segmenti içinde bol miktarda kan ve pihtı izlendi (Resim 1). Makroskopik olarak lümeni çepeçevre saran ülsere alanları vardı (Resim 2). Patolojik preparatlarda da kazeifiye granülomlar belirgin bir şekilde görülmekteydi (Resim 3). Ameliyat sonrası hastanın vital bulguları dramatik olarak düzeldi ve Hgb değeri 8 gr/dl'de stabil olarak seyretti. Drenlerinden geleni olmayan, rektal kanaması düzelen ve vitalleri stabil giden hasta, antitüberküloz tedavisinin devam etmesi için göğüs hastalıkları hastanesine yönlendirildi.

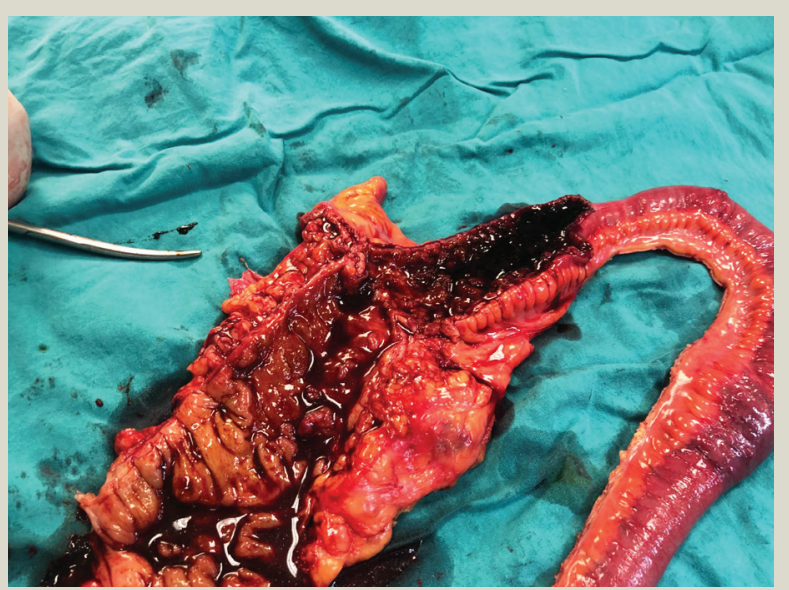

Resim 1. Çıkarılan barsak lümeninde yoğun kan ve pıhtı görülmekte.

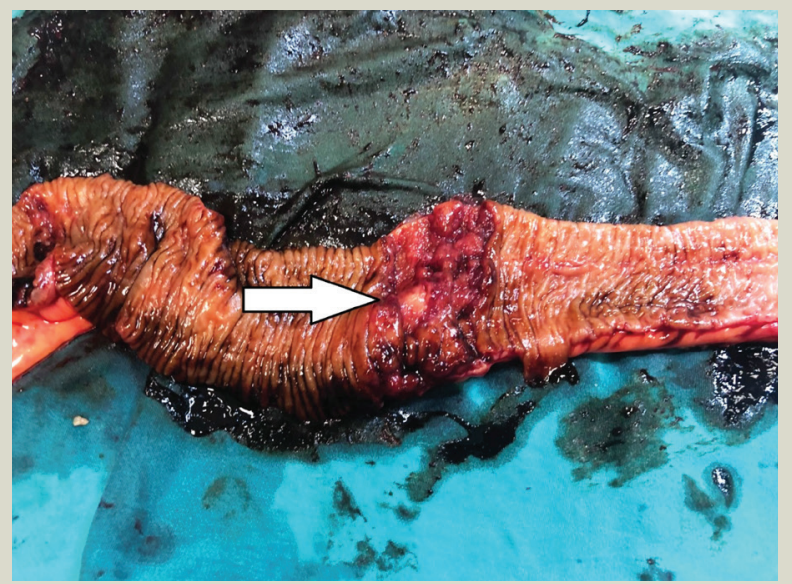

Resim 2. Lümeni çepeçevre saran ülsere ve hemorajik alan (beyaz ok).

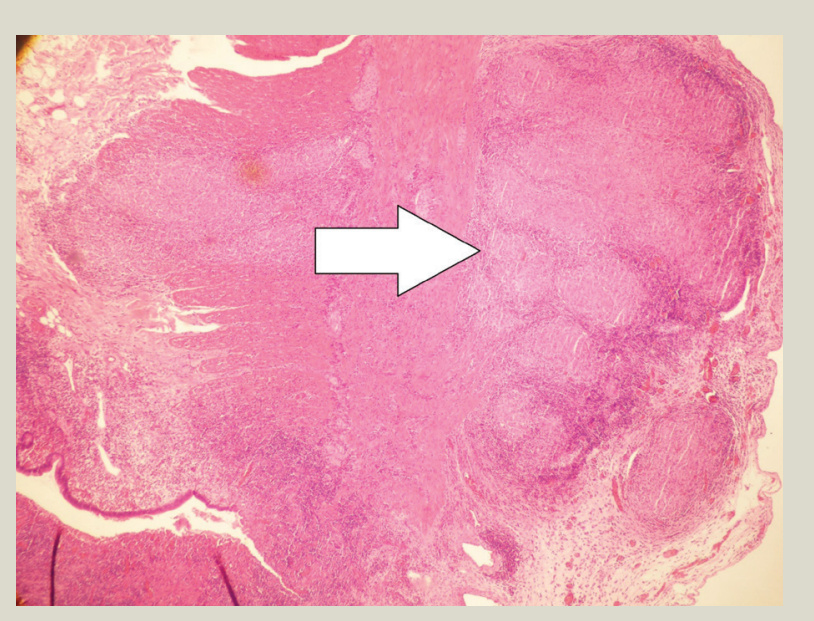

Resim 3. Yaygın kazeifiye granülomlar (beyaz ok)

\section{TARTISSMA}

Tüberküloz gastroenteriti klinikte silik, kronik ve non-spesifik şikayetlerle kendini gösterir. Gece terlemesi, ateş, karın ağrısı ve ishal bunlardan en sık görülenlerdir. Bununla beraber hastalığın klinikte akut prezentasyonları da olmaktadır. Akut intestinal obstrüksiyon ve perforasyon bunlardandır. Masif kanama literatürde 12 'den az hastada bildirilmiş, diğerlerine göre daha nadir görülen bir başvuru şikayetidir $(5,6)$. Biz de burada masif alt GIS kanaması ile kendini gösteren TG'li olgumuzu sunduk.

Abdominal tüberküloz klinikte kendini birçok farklı şekilde gösterebilir ve bu nedenle de çoğu hastalığın ayırıcı tanısına girer. Bunlardan en önemlisi ve en iyi bilineni Crohn hastallğıdır (7). Tüberküloz gastroenteritinde en sık tutulan bölgenin ileoçekal alan olması her iki hastalık için ayırıcı tanının dikkatli bir şekilde yapılmasını gerektirir. Crohn hastalığının temel tedavileri olan immünsüpresif tedaviler, TG'de morbidite ve mortaliteye yol açabilir (8). Crohn hastalığı ve TG ayrımı için iyi tanımlanan endoskopik ve radyolojik özellikler şöyle sıralanabilir. Crohn hastalığında lümene paralel olarak uzanan ülserler TG'de lümene dik seyreder. Görüntüleme yöntemlerinde barsak duvar kalınlık artışına ilave olarak genişlemiş paraaortik lenf nodları olması, duvar kalınlık artışının asimetrik olması, assit varlı̆̆ ve omentum tutulumu TG lehine bulgulardır (9). Tanısal ayrımı doğru yapılmayan ve Crohn ön tanısıyla immünsüpresif tedavi alan TG hastaları hayatı tehdit eden potansiyel komplikasyonlara adaydır.

Tüberküloz gastroenteritinin alt GİS kanamalarındaki sıklığı konusunda literatürde yer alan eski çalıșmalar \%5'lik bir oran verse de günümüzde bu oranın çok daha nadir olduğu tahmin edilmektedir (6). Diğer etiyolojik nedenlerde olduğu gibi TG'ne bağlı alt GIS kanamalarında da kolonoskopi ve eşlik eden hemostatik teknikler birinci basamak tedavi yöntemidir. Cerrahi, endoskopinin yetersiz kaldığı kanamalarda başarılı bir alternatif yöntem olarak kullanılmaktadır. Özellikle çıkan 
kolon ve çekum lokalizasyonu kanamalarda kolonoskopun bu bölgere ulaşamaması ve/veya masif kanamaya bağlı lezyon değerlendirmesinin, distaldekilere göre daha zor olması bu bölge kökenli masif kanamalarda endoskopik hemostazın başarısını azaltmaktadır. Bizim hastamız her ne kadar ilk başvurusunda kolonoskopiyi istemese de, klinik seyrinde görülen masif rektal kanama, olası bir endoskopik müdahaleyi ileri derecede güçleştiren bir durum olarak karşımıza çıkabilirdi.

\section{KAYNAKLAR}

1. Horvath KD, Whelan RL. Intestinal tuberculosis: return of an old disease. Am J Gastroenterol 1998;93:692-6.

2. Akhan O, Pringot J. Imaging of abdominal tuberculosis. Eur Radiol 2002;12:312-23.

3. Debi U, Ravisankar V, Prasad KK, Sinha SK, Sharma AK. Abdominal tuberculosis of the gastrointestinal tract: revisited. World J Gastroenterol 2014;20:14831-40.

4. Ndububa DA, Olasode BJ, Olatunde LO. Abdominal tuberculosis with fatal gastro-intestinal haemorrhage. Cent Afr J Med 1997;43:175-7.

5. Verma P, Kapur BM. Massive rectal bleeding due to intestinal tuberculosis. Am J Gastroenterol 1979;71:217-9.
Sonuç olarak Crohn hastalığı ve TG, birbirleriyle karışabilen, tedavileri tamamen farklı iki önemli hastalık olup kolonoskopi, eşlik eden biyopsi ve kültür yöntemleriyle ayırıcı tanı dikkatli bir şekilde yapılmalıdır. Tüberküloz gastroenteriti tanısı alan bir olguda, nadir de olsa masif rektal kanamanın görülebileceği ve endoskopik hemostazın yapılamadığı ve/ veya başarısız olduğu olgularda cerrahinin başarılı bir alternatif tedavi yöntemi olabileceği akılda tutulmalıdır.

\section{"Tüm yazarlar herhangi bir çıkar çatışması olmadı̆̆ını kabul ederler."}

6. Kela M, Agrawal A, Sharma R, Agarwal R, Agarwal VB. Ileal tuberculosis presenting as a case of massiverectal bleeding. Clin Exp Gastroenterol 2009;2:129-31.

7. Hu ML, Lee CH, Kuo CM, et al. Abdominal tuberculosis: analysis of clinical features and outcome of adult patients in southern Taiwan. Chang Gung Med J 2009;32:509-16.

8. Adegbola SO, Sahnan K, Warusavitarne J, Hart A, Tozer P. Anti-TNF therapy in Crohn's disease. Int J Mol Sci 2018;19:pii: E2244.

9. Goyal P, Shah J, Gupta S, Gupta P, Sharma V. Imaging in discriminating intestinal tuberculosis and Crohn's disease: past, present and the future. Expert Rev Gastroenterol Hepatol 2019;13:995-1007. 